\title{
Inteligência Emocional: Um Estudo de Validade sobre a Capacidade de Perceber Emoções
}

\author{
José Maurício Haas Bueno ${ }^{1}$ \\ Universidade São Francisco \\ Universidade Presbiteriana Mackenzie \\ Ricardo Primi \\ Universidade São Francisco
}

\begin{abstract}
Resumo
Investigou-se a validade e as propriedades psicométricas de uma escala para mensuração da capacidade de perceber emoções em expressões faciais, músicas, quadros e relatos pessoais (histórias), que se supõem ligada à inteligência emocional. Essa variável foi correlacionada com traços de personalidade (16PF), inteligência (BPR-5), e com o desempenho dos participantes numa tarefa de Psicodiagnóstico. Foram participantes 76 alunos do $5^{\circ}$ ano do curso de Psicologia, com idades entre 21 e 50 anos, estagiários na disciplina de Psicodiagnóstico, além de 8 professores supervisores da mesma disciplina. Os protocolos foram pontuados por 3 métodos: concordância com o consenso, concordância com especialistas e concordância com a pessoa-alvo. Discutiu-se alguns problemas metodológicos relacionados a esses critérios de pontuação. Obtiveram-se correlações estatisticamente significativas com o traço de praticidade, com o estilo de resposta administração da imagem, e com raciocínio espacial; somente a subescala faces apresentou correlação estatisticamente significativa com o desempenho no estágio em Psicodiagnóstico.

Palavras-chave: Inteligência; avaliação psicológica; personalidade.
\end{abstract}

Emotional Intelligence: A Validity Study of Emotional Perception Ability

\begin{abstract}
This work investigated the validity and psychometric properties of an emotional perception scale in four types of stimuli: faces, music, designs and self-reports (stories), which is supposed to be related to emotional intelligence. These variables were correlated with personality traits (16PF), intelligence (BPR-5), and academic achievement in psychodiagnostic discipline. Participants were 76 undergraduates psychology students, aged between 21-50 years old and 8 lecturers who were supervising these students. The protocols of emotion perception were scored according to 3 methods: agreement with consensus, agreement with experts and agreement with the target. Although we have adopted the agreement with consensus to verify the correlations with other criteria some methodological problems of this scoring method for an intelligence test were discussed. Significant correlations of emotional perception with spatial reasoning and with achievement in psychodiagnosis course were obtained, but in the latter only with faces subtest.

Keywords: Intelligence; psychological assessment; personality.
\end{abstract}

O termo "inteligência emocional" foi utilizado pela primeira vez num artigo de mesmo nome, no qual é apresentado como uma subclasse da Inteligência Social, cujas habilidades estariam relacionadas ao "monitoramento dos sentimentos e emoções em si mesmo e nos outros, na discriminação entre ambos e na utilização desta informação para guiar o pensamento e as ações" (Salovey \& Mayer, 1990, p. 189). A utilização de processos relacionados à Inteligência Emocional se inicia quando uma informação carregada de afeto entra no sistema perceptual, envolvendo os seguintes componentes: a) avaliação e expressão das emoções em si e nos outros; b) regulação da emoção em si e nos outros; e c) utilização da emoção para adaptação. Esses processos ocorrem tanto para o processamento de informações verbais, quanto não-verbais (Salovey \& Mayer, 1990).

\footnotetext{
${ }^{1}$ Endereço para correspondência: Rua Maricota José, 75, 13253 220, Jardim América, Itatiba, SP. E-mail: avalpsi@uol.com.br
}

Em 1997, Mayer e Salovey apresentam uma revisão ampliada, clarificada e melhor organizada do modelo de 1990, que enfatizava a percepção e controle da emoção, mas omitia o pensamento sobre sentimento. Nas palavras dos autores, a definição que corrige esses problemas é a seguinte:

A Inteligência Emocional envolve a capacidade de perceber acuradamente, de avaliar e de expressar emoções; a capacidade de perceber e/ou gerar sentimentos quando eles facilitam o pensamento; a capacidade de compreender a emoção e o conhecimento emocional; e a capacidade de controlar emoções para promover o crescimento emocional e intelectual. (Mayer \& Salovey, 1997, p. 15)

O processamento de informações emocionais é explicado através de um sistema de quatro níveis, que se organizam de acordo com a complexidade dos processos psicológicos que apresentam: a) percepção, avaliação e expressão da emoção; 
b) a emoção como facilitadora do pensamento; c) compreensão e análise de emoções; emprego do conhecimento emocional; e d) controle reflexivo de emoções para promover o crescimento emocional e intelectual, descritos a seguir.

A percepscão, avaliação e expressão da emoção abrangem desde a capacidade de identificar emoções em si mesmo, em outras pessoas e em objetos ou condições físicas, até a capacidade de expressar essas emoções e as necessidades a elas relacionadas, e ainda, a capacidade de avaliar a autenticidade de uma expressão emocional, detectando sua veracidade, falsidade ou tentativa de manipulação. A emoşão como facilitadora do ato de pensar diz respeito à utilização da emoção como um sistema de alerta que dirige a atenção e o pensamento para as informações (internas ou externas) mais importantes. A capacidade de gerar sentimentos em si mesmo pode ajudar uma pessoa a decidir, funcionando como um "ensaio", no qual as emoções podem ser geradas, sentidas, manipuladas e examinadas antes da tomada de decisão. $A$ compreensão $e$ análise de emoções (conhecimento emocional) incluem desde a capacidade de rotular emoções, englobando a capacidade de identificar diferenças e nuances entre elas (como gostar e amar), até a compreensão da possibilidade de sentimentos complexos, como amar e odiar uma mesma pessoa, bem como as transições de um sentimento para outro, como a de raiva para a vergonha, por exemplo. Finalmente, o controle reflexivo das emocões para promover o crescimento emocional e intelectual refere-se à capacidade de tolerar reações emocionais, agradáveis ou desagradáveis, compreendê-las sem exagero ou diminuição de sua importância, controlá-las ou descarregá-las no momento apropriado.

Esse modelo de quatro níveis acabou sendo reduzido a um modelo de três níveis correspondentes à percepção, compreensão e controle de informações carregadas de afeto em decorrência de estudos fatoriais de validade de construto (Mayer, Salovey \& Caruso, 2000). Nesse trabalho, focalizarse-á apenas a primeira ramificação do construto, relacionado à capacidade de perceber emoções.

\section{Mensuração: Tipos de Instrumentos e Critérios de Pontuação}

Um dos problemas mais evidentes relacionado à inteligência emocional é o de sua mensuração. Desde a proposição da inteligência social (Thorndike, 1920) que não se consegue desenvolver um instrumento confiável para medi-la. E sem esse recurso não é possível conhecer objetivamente suas características funcionais (e estruturais, mas esse é um outro problema) na mente humana.

A principal discussão se dá em torno dos tipos de instrumentos utilizados para mensuração dessas formas de inteligência que têm sido propostos ao longo da história.
Esses instrumentos têm sido, invariavelmente, baseados em auto-relato, isto é, instrumentos que colhem a opinião do sujeito a respeito de si próprio na área que se pretende investigar. Assim, se pretende-se mensurar o quanto o sujeito é ansioso, apresentam-lhe frases contendo os sintomas, pensamentos e formas de se comportar de pessoas ansiosas para que classifique se e/ou quanto cada item apresentado se aplica ao seu caso.

Esse tipo de mensuração, que tem sido utilizada com sucesso para avaliação de traços de personalidade, é inadequado para mensuração da inteligência. Supõe-se que, sendo a inteligência uma capacidade cognitiva, esta deva ser medida através do desempenho do sujeito em tarefas nas quais demonstre possuir tal capacidade (medidas de desempenho). Não faz sentido mensurar qualquer tipo de inteligência perguntando-se ao sujeito o quanto ele se considera inteligente, ou o quanto ele se considera capaz de resolver problemas deste ou daquele tipo. Esta seria uma medida de algo como a auto-percepção da capacidade de resolver problemas, porém não relacionada diretamente à real capacidade do sujeito em questão. Portanto, ao se propor a inteligência emocional como um tipo de inteligência, deve-se apresentar um instrumento composto de tarefas cuja resolução dependeriam do uso de capacidade.

No entanto, a maioria das escalas construídas para avaliação da inteligência emocional tem se baseado em autorelato, como por exemplo o O BarOn Emotional Quotient Inventory (BarOn Eq-i) (Bar-On, 1996, 1997) e a Medida de Inteligência Emocional (Siqueira, Barbosa \& Alves, 1999), para citar apenas uma estrangeira e uma nacional, respectivamente. Ambos os instrumentos apresentam rigorosos estudos de construção, assim como boas propriedades psicométricas, mas são compostos de subescalas tradicionalmente associadas à traços de personalidade, habilidades sociais e outros construtos que não a inteligência.

O primeiro instrumento baseado em desempenho para avaliação da inteligência emocional lançado comercialmente foi a Multifactor Emotional Intelligence Scale (MEIS, Mayer, Salovey \& Caruso, 1997). Esse instrumento é composto por 12 tarefas destinadas a investigar quatro ramificações da inteligência emocional (Mayer \& Salovey, 1997): identificação das emoções, utilização das emoções, compreensão das emoções e gerenciamento das emoções. A primeira ramificação desse instrumento, relacionada à percepção de emoções, é constituída de tarefas em que os participantes têm de avaliar a presença de determinadas emoções em quatro tipos de estímulos: faces, músicas, quadros e histórias. A subescala histórias representa o estímulo verbal e as outras três os estímulos não-verbais. Essa ramificação da MEIS foi utilizada como base para o desenvolvimento desse projeto. 
Além do tipo de instrumento relatado acima, também há um problema relacionado ao critério de avaliação. Os instrumentos baseados em desempenho requerem que, para cada item apresentado, conheça-se a resposta que será considerada como correta. Essa é a principal diferença entre instrumentos baseados em desempenho e em auto-relato: $\mathrm{o}$ segundo não trabalha com respostas corretas, mas com respostas características. Em testes tradicionais de inteligência, quando um problema é proposto, já se sabe de antemão qual é a resposta certa. No caso das tarefas relacionadas à inteligência emocional, como escolher a resposta a ser considerada como correta? Os critérios que têm sido utilizados nas pesquisas relacionadas à inteligência emocional são descritos a seguir (Davies, Stankov \& Roberts, 1998; Mayer, DiPaolo \& Salovey, 1990; Mayer \& Geher, 1996).

O primeiro deles é baseado na resposta consensual (consenso) dos participantes que responderam ao teste. Esse critério foi definido como "a habilidade de perceber emoções que são consensualmente definidas como presentes e igualmente concordar quando a emoção não estiver presente" (Mayer \& cols., 1990, p. 776). Em termos de pontuação, uma resposta é considerada consensual quando estiver dentro da margem de mais ou menos um ponto em relação ao valor modal. Uma outra alternativa é considerar o peso do grupo com o qual concordava o julgamento do participante (Ex.: se um participante escolher uma alternativa juntamente com $90 \%$ do grupo de participantes, então 0,9 será adicionado à sua respectiva pontuação).

Outro critério utilizado é a concordância com a pessoaalvo. Pessoa-alvo é a pessoa que produziu o estímulo utilizado. As pessoas que cederam os estímulos utilizados nos instrumentos também responderam às mesmas questões apresentadas posteriormente aos participantes que se submetem ao teste, porém, suas respostas são consideradas como um referencial já que a proposição dos testes é avaliar o que eles estariam sentindo no momento em que o estímulo foi produzido. Segundo esse critério, o testando recebe um ponto toda vez que sua resposta concorda com a resposta da pessoa-alvo.

Semelhante ao critério anterior é a concordância com especialistas. Nesse caso o referencial utilizado é uma avaliação realizada por profissionais, que decidem as respostas consideradas como corretas, baseados em teorias e pesquisas relacionadas ao tema. Por esse critério, o testando recebe um ponto cada vez que sua resposta concorda com a dos especialistas.

Além dessas possibilidades, pode-se citar a utilização de outros critérios como a intensidade e a amplitude das emoções percebidas. A intensidadeéuma nota correspondente à média e a amplitude ao desvio-padrão em relação às respostas dos participantes ao longo de todos os itens de cada escala.

Em vários estudos, a convergência entre os métodos de pontuação foi estudada. Num deles foram encontradas baixas correlações entre as pontuações por consenso, intensidade e amplitude (Mayer \& cols., 1990); em outros, no entanto, os pesquisadores relatam ter encontrado convergência entre os sistemas de pontuação por consenso, especialistas e pessoa-alvo (Mayer \& cols., 2000), e entre concordância com o consenso e com a pessoa-alvo na avaliação da subescala histórias (Mayer \& Geher, 1996). Em todos os casos, ainda, a pontuação baseada na concordância com o consenso apresentou os melhores resultados com a relação à consistência interna.

\section{Medidas de Inteligência Emocional: Evidências de Validade e Precisão}

Nos estudos relacionados à inteligência emocional, Mayer, Salovey e colaboradores (1990, 1996, 1997, 2000) procuraram evidências de que a inteligência emocional pudesse ser considerada como uma inteligência independente das inteligências anteriormente propostas e já estabelecidas e aceitas no meio científico (validade discriminante), assim como também apresentasse uma certa variância em comum com outros tipos de inteligência para poder ser considerada uma inteligência (validade convergente). Também investigaram as relações entre as medidas de inteligência emocional e construtos de personalidade, tais como empatia e alexitimia, que dizem respeito a capacidade de compreender os outros a partir de seus pontos de vista e à incapacidade de nomear e expressar sentimentos próprios, respectivamente. Finalmente, a validade fatorial também foi estudada aplicando-se análise fatorial de primeira e segunda ordem para investigar a dimensionalidade do construto.

Num experimento para a investigação da percepção de emoções em expressões faciais, cores e desenhos abstratos (Mayer \& cols., 1990), utilizando os critérios de pontuação por concordância com o consenso, intensidade e amplitude das emoções percebidas citados anteriormente, encontraram: a) solução unifatorial para a pontuação por consenso, indicando que a percepção emocional pode ser generalizada para os três domínios investigados; b) alta fidedignidade (coeficiente $\alpha$ ) para as pontuações por intensidade $(\alpha=0,94)$ e amplitude $(\alpha=0,90)$, porém baixa para pontuação por consenso $(\alpha=0,63)$; e c) correlações estatisticamente significativas entre as seguintes variáveis: concordância com o consenso e empatia $(r=0,33 ; p<0,001)$, consenso e extroversão $(r=0,15 ; p<0,05)$, amplitude e intensidade das emoções percebidas e alexitimia $(r=0,16, p<0,05$ e $r=0,20$, $p<0,01$, respectivamente), e amplitude e intensidade das emoções percebidas e neuroticismo $(r=0,23, p<0,001$ e $r=0,22$, 
$p<0,01$, respectivamente). As correlações positivas com alexitimia e neuroticismo foram explicadas pelos autores em razão das escalas utilizadas para essas medições. Eles alegam que ambas, Toronto Alexithymia Scale e Eysenck. Neuroticism Scale, na verdade, captam melhor angústia, tristeza, dor (distress), do que os fatores a que se propõem investigar e, nesse caso, faria sentido pensar que tais indivíduos tendem a perceber afetos negativos com maior intensidade e a experimentar alterações de humor com maior freqüência.

Os resultados de outro experimento envolvendo informações verbais (Mayer \& Geher, 1996) indicaram que apenas a pontuação por concordância com o consenso apresentou alta fidedignidade $(\alpha=0,92)$, e que não houve correlação estatisticamente significativa entre as pontuações por consenso e pessoa-alvo, nem entre estes dois critérios e o auto-relato dos participantes-alvo. Os participantes que obtiveram as maiores pontuações por concordância com o consenso e com a pessoa-alvo também obtiveram as maiores pontuações numa escala de empatia e no Schoolastic Aptitude Test (SAT), e os menores escores numa escala de defensividade. Esses resultados foram interpretados como evidência de que a solução de problemas emocionais requer tanto a abertura emocional quanto inteligência geral.

Finalmente, Mayer e colaboradores (2000) publicam um estudo bastante completo sobre os critérios que uma "inteligência" deve preencher para ser legitimada como tal, e investigam, através da MEIS, se o modelo por eles proposto preenche esses critérios, que, a saber, são: a) deve permitir a operacionalização em grupos de habilidades; b) deve preencher certos requisitos correlacionais, ou seja, deve estar moderadamente correlacionada com inteligências anteriormente definidas (para ser considerada como um inteligência) e ainda apresentar alguma variância única (para ser considerada independente das demais); e c) as habilidades do modelo proposto devem desenvolver-se com a idade e a experiência.

Os resultados dessa investigação mostraram que: a) a inteligência emocional pode ser operacionalizada num conjunto de habilidades, que foram apresentadas como tarefas para serem realizadas pelo sujeito (MEIS); b) essas tarefas possuem respostas que podem ser claramente distintas entre melhores e piores, conforme indicou a convergência entre os três métodos de pontuação utilizados (consenso, especialistas e alvo); c) todas as tarefas apresentaram correlações mutuas, independentemente do método de pontuação empregado; d) a inteligência emocional correlacionou-se moderadamente com medidas de inteligência verbal, indicando que possui alguma variância em comum com outra forma de inteligência, mas também alguma variância única; e) a inteligência emocional mostrou- se promissora como preditora de outras qualidades, tais como, empatia, estilo parental (calorosidade emocional dos pais, capacidade para ouvir os filhos, conduta nãoabusiva, flexibilidade, etc.) e atividades de vida nos aspectos culturais, crescimento pessoal e entretenimento; f) adultos tiveram um desempenho melhor do que adolescentes, evidenciando que a inteligência emocional se desenvolve com a idade e a experiência, apesar de manter em adolescentes as mesmas relações com empatia e inteligência verbal observadas em adultos; e finalmente g) a escala produziu quatro fatores, um primeiro fator geral de inteligência emocional, que pode ser subdividido em três subescalas: percepção, compreensão e gerenciamento de informações carregadas de afeto, reduzindo o modelo inicial de quatro níveis para um modelo com três níveis.

Um outro grupo de pesquisadores, no entanto, encontrou resultados menos encorajadores. Davies e colaboradores (1998) publicaram um artigo contendo três estudos, cujos principais objetivos eram: a) examinar o status empírico das medidas de inteligência emocional por auto-relato e por desempenho em tarefas específicas; b) determinar as relações que a inteligência emocional possa ter com habilidades cognitivas tradicionais, incluindo índices de inteligência fluída, cristalizada e social; e c) examinar a relação entre os vários tipos de medidas de inteligência emocional e variáveis relacionadas à personalidade, incluindo medidas dos seis tipos de personalidade (extroversão, neuroticismo, psicoticismo, conscienciosidade, socialização e abertura).

O primeiro estudo incluiu uma ampla gama de medidas de inteligência emocional, tanto por auto-relato quanto por desempenho, além de outras, como habilidades cognitivas, inteligência fluída e cristalizada, inteligência social e traços de personalidade. As principais medidas de inteligência emocional por desempenho eram as provas de percepção de emoções em faces, cores, músicas e sons, com pequenas modificações em relação às utilizadas por Mayer e colaboradores (1990).

Foram encontradas algumas evidências que apóiam e outras que não apóiam as validades das medidas e do construto. Por exemplo, a favor da validade contam as correlações negativas encontradas entre medidas de alexitimia e de inteligência emocional (avaliada tanto por auto-relato quanto por desempenho), e as intercorrelações entre as quatro escalas de percepção de emoções (faces, cores, músicas e sons) que confirmam a hipótese de Mayer e colaboradores (1990) de que o julgamento consensual de emoções se generaliza por entre diferentes tipos de estímulos. Contra essas evidências, contudo, conta o fato de que essas mesmas quatro escalas, apesar de se apresentarem agrupadas isoladamente em um único fator (percepção de emoções), não se correlacionaram significativamente nem 
com medidas de inteligência emocional por auto-relato, nem com variáveis de habilidades cognitivas e personalidade, contradizendo o postulado de Salovey e Mayer de que tais habilidades incluiriam um conjunto de habilidades conceitualmente relacionadas; além disso, altas correlações entre medidas de inteligência emocional por auto-relato e traços de personalidade levaram os autores a sugerir que a inteligência emocional pode não ser inteiramente distinta de construtos relacionados à personalidade.

Uma análise fatorial exploratória (dos componentes principais com rotação oblimin) realizada com as 30 variáveis incluídas nesse primeiro estudo, resultou em oito fatores. $\mathrm{O}$ primeiro deles foi capaz de explicar apenas $15 \%$ da variância total, considerado muito fraco para confirmar validade unifatorial do construto estudado. Os oito fatores encontrados foram relacionados a neuroticismo, psicoticismo, extroversão, clareza emocional, conhecimento emocional, percepção de emoções, inteligência cristalizada e inteligência fluída. Esse conjunto de fatores foi capaz de explicar $64 \%$ da variância total encontrada.

Entre esses fatores, aqueles que supostamente estariam relacionados à inteligência emocional conforme proposta por Salovey e Mayer (1990), clareza emocional, conhecimento emocional e percepção de emoções (faces, cores, música e sons), se mostraram totalmente independentes tanto da inteligência cristalizada quanto da inteligência fluída. Além disso, os autores também concluíram que outros componentes da inteligência emocional, como regulação emocional, expressão emocional e ambos impulsividade e empatia, apresentaram cargas em fatores tipicamente relacionados à dimensões da personalidade, como neuroticismo, extroversão e psicoticismo, cujos construtos já foram extensivamente demonstrados como independentes de habilidades cognitivas.

Também foram levantados dois problemas metodológicos relacionados à mensuração da percepção de emoções. O primeiro problema diz respeito à utilização da resposta consensual como critério para pontuação das respostas corretas. No mínimo, argumentam, é preciso investigar se a resposta consensual é a que melhor representa as emoções realmente presentes nos estímulos apresentados. O segundo problema se refere à baixa consistência interna encontrada em três dos quatro subtestes: 0,58 para faces, 0,55 para músicas e 0,36 para cores. Tais resultados indicam que boa parte das variações encontradas entre os participantes se devem mais a erros de medida do que a variações verdadeiras na habilidade em questão, colocando sob suspeita os resultados derivados dessas medidas.

Os resultados apresentados não são nem totalmente contra as evidências de validade do construto, nem tampouco totalmente a seu favor. Podem ser interpretados como encorajadores se se levar em conta a dificuldade histórica em relação ao construto, ou como desanimadores, se comparados com os resultados obtidos com outras formas de inteligência já consagradas no meio científico. Como as investigações de validade realizadas até o presente momento só apresentam evidências baseadas em critérios cujas observações foram colhidas através de outros instrumentos; como nenhuma evidência de predição de desempenho em atividades da vida real foi apresentado; e como no Brasil não existe nenhum estudo relacionado a esse construto baseado em medições de desempenho dos participantes, optou-se pela realização desse projeto com a pretensão de contribuir, ainda que de forma limitada, para o preenchimento dessas lacunas. Assim, o objetivo geral desse trabalho foi investigar a validade de um instrumento para avaliação da capacidade de perceber emoções, em um grupo de estudantes de Psicologia; e, mais especificamente, verificar as propriedades psicométricas do instrumento e investigar sua validade concorrente em relação aos seguintes critérios: desempenho dos participantes no estágio em Psicodiagnóstico, segundo a avaliação de seus supervisores; e desempenho dos participantes em medidas de inteligência e personalidade.

Foram levantadas as seguintes hipóteses:

1) Os estagiários que apresentarem os melhores desempenhos na avaliação da capacidade de perceber emoções, também obterão os melhores resultados de desempenho no estágio em Psicodiagnóstico;

2) Devem ser encontradas correlações baixas, porém estatisticamente significativas e simultâneas, entre os escores da capacidade de perceber emoções e as avaliações de inteligência e personalidade. Em relação à inteligência são esperadas correlações baixas tanto com raciocínio verbal quanto com espacial. Isto é esperado especialmente em relação ao raciocínio verbal, indicando a validade discriminante do construto de inteligência cristalizada avaliada por este teste. Em relação à personalidade são esperadas correlações positivas e significativas com os fatores Inteligência $(\mathrm{B}+)$, Estabilidade Emocional $(\mathrm{C}+)$, Brandura (I+), Imaginação $(\mathrm{M}+)$, e correlações negativas e significativas com os fatores Apreensão (O-), Confiança (L-) e Tensão (Q4-). Os Fatores C, L, O e Q4 compõem o Fator Global Ansiedade (Neuroticismo), e os Fatores I e M estão associados à abertura ao processamento e informações emocionais;

3) As quatro subescalas de percepção de emoções devem apresentar correlações positivas e significativas entre si, bem como solução unifatorial. 


\section{Método}

\section{Participantes}

Participaram desse estudo 76 alunos do $5^{\circ}$ ano do curso de Psicologia, predominantemente do sexo feminino, com idades variando entre 21 e 50 anos $(m=26,5, d p=6,4)$, estagiários na disciplina de Psicodiagnóstico, e 8 professores supervisores da mesma disciplina. Cada professor supervisionou os atendimentos de no máximo 15 alunos (em grupos de no máximo 9 alunos), e cada aluno foi supervisionado por apenas um professor no período referente a realização desse estudo. A escolha da amostra justifica-se por dois motivos principais: a importância da capacidade de perceber emoções neste contexto e a possibilidade de coletar informações sobre os participantes numa situação de desempenho.

\section{Instrumentos e Procedimentos}

\section{Provas de avaliação da percep̧̧ão de emoções adaptada para aplicação} coletiva

Utilizou-se apenas as provas da subescala "percepção de emoções" da Escala Multifatorial de Inteligência Emocional (MEIS, Mayer \& cols., 1997), cujos itens são constituídos por oito expressões faciais, oito trechos musicais, oito desenhos abstratos e seis relatos pessoais. Para os três primeiros grupos de itens (faces, quadros e trechos musicais), os participantes avaliaram a presença ou ausência de seis emoções básicas (raiva, tristeza, alegria desgosto, medo e surpresa), atribuindo pontos de 1 a 5 , conforme considerassem a emoção totalmente ausente (1) até totalmente presente (5), respectivamente. Os seis relatos pessoais devem ser avaliados na mesma escala de 1 a 5, conforme o participante considere que o sujeito que relatou o fato estivesse se sentindo: invejoso, cheio de vida, envergonhado, calmo, aberto, cheio de energia e feliz. Os estímulos foram projetados em uma tela, com exceção dos sons, que foram reproduzidos através de arquivos de computador. Os participantes assinalaram suas respostas em uma folha apropriada.

\section{Inventário dos 16 fatores de personalidade (16PF)}

Esse instrumento investiga traços de personalidade através de um inventário constituído por 185 itens. Inicialmente, são obtidos 16 fatores primários e, a partir da combinação de alguns destes, são obtidos mais 5 fatores gerais. Todas as escalas são obtidas em estenos, que podem variar de 1 a 10, e são bipolares, isto é, pontuações altas (8 a 10) e baixas ( 1 a 3 ) tem sentidos opostos, enquanto que valores intermediários ( 4 a 7 ) representam equilibrio no traço em consideração. Além disso, são obtidos ainda três índices percentilicos referentes ao estilo de respostas do sujeito, a saber: administração da imagem (AI), respostas de nãofreqüência (NF) e aquiescência (AQ) (R. B. Cattell, A. K. S. Cattell \& H. E. P. Cattell, 1993). Embora o manual do instrumento não apresente evidências de validade e precisão para a população brasileira, alguns estudos recentes já trazem estas informações indicando que o instrumento atende as exigências de qualidade básicas em termos de requisitos psicométricos (Primi \& cols., 2002; Vendrusculo, 2002).

\section{Bateria de provas de raciocinio (BPR-5)}

Para este estudo, foi utilizada apenas a prova de raciocínio verbal (RV) e a de raciocínio espacial (RE) da Bateria de Provas de Raciocínio (BPR-5), que, em sua forma completa, inclui ainda as provas de raciocínio abstrato, mecânico e numérico. A prova de raciocínio verbal é composta por 25 itens envolvendo analogias entre palavras, em tarefas nas quais o sujeito deve analisar a relação entre duas palavras dadas, aplicando-a para a resolução de uma segunda relaçãoproblema. O tempo para resolução desta prova é de 10 minutos. A prova de raciocínio espacial é composta de 20 itens, todos eles constituídos por cubos em diferentes posições, sendo que a tarefa do sujeito é descobrir o padrão seqüencial do movimento dos cubos e aplicá-lo para descobrir o último movimento (incógnito). Para essa tarefa o tempo de execução máximo é de 18 minutos. Optou-se por essas duas provas pelo fato de a primeira estar mais relacionada à inteligência cristalizada $(\mathrm{gc})$ e a segunda ao processamento visual (gv) e inteligência fluida (gf) (Primi \& Almeida, 2000a, 2000b). Para cada resposta certa, atribuise um ponto, e o escore bruto de cada sujeito nessas provas foi transformado em resultado padronizado por idade, cuja média foi estabelecida como 100 e o desviopadrão 15. O escore geral em inteligência (EG) foi obtido através da média aritmética dos resultados padronizados nas duas provas de raciocínio.

\section{Avaliação dos supervisores}

Foi utilizado um instrumento para avaliação do desempenho dos alunos no estágio em Psicodiagnóstico, segundo o julgamento de seus respectivos professores supervisores (Bueno \& Primi, 2003). O instrumento fornece um escore total, relacionado ao desempenho geral no estágio em psicodiagnóstico, e três subescalas derivadas da primeira, que informam sobre três diferentes aspectos da atuação em psicodiagnóstico. O Fator 1 (AS-F1) se refere ao desempenho técnico do aluno em seus atendimentos; o Fator 2 (AS-F2) à competência emocional para atendimento clínico; e o Fator 3 (AS-F3) está relacionado à habilidades sociais tanto nos atendimentos quanto nas supervisões. As pontuações em cada fator foram divididas pelo número máximo de pontos possíveis nos mesmos, de forma a obter sempre resultados entre 0 e 1. 


\section{Aplicação dos instrumentos}

A aplicação dos instrumentos nos alunos foi realizada coletivamente, em sala de aula, em duas sessões, uma para a aplicação da avaliação da capacidade de perceber emoções, e outra para a aplicação do $16 \mathrm{PF}$ e das provas de raciocínio verbal e espacial da BPR-5. A avaliação dos supervisores foi colhida através do instrumento acima descrito, que foi entregue para preenchimento e posteriormente recolhido.

Os participantes foram informados a respeito dos objetivos e procedimentos dessa pesquisa, da participação voluntária e da possibilidade de sua retirada se assim o desejassem. Assinaram um termo de consentimento informado, autorizando a coleta e utilização dos dados para essa pesquisa.

\section{Resultados e Discussão}

Em razão do grande número de instrumentos utilizados para coleta de dados, os resultados serão apresentados em dois grandes blocos: o primeiro contém as propriedades psicométricas da Escala de Percepção de Emoções, e o segundo contém os resultados correlacionais dessa com as medidas de critério.

\section{Estudo das propriedades psicométricas da Escala de Percepção de Emoções da MEIS}

Para análise da capacidade de perceber emoções, computaram-se três tipos de escores descritos anteriormente: concordância com o consenso, concordância com especialistas e concordância com a pessoa alvo. A pontuação por concordância com o consenso foi a igual à proporção de pessoas que escolhiam a mesma resposta. Por exemplo, se a proporção de participantes que escolhiam 2 a um determinado item fosse $35 \%$, então a pessoa que escolhesse esta resposta teria 0,35 acrescentado à sua pontuação. Esta pontuação foi efetuada em relação à amostra americana, para as subescalas faces e quadros (os dados dessa padronização foram cedidos pelos pesquisadores americanos, Mayer \& cols., 1997), e também em relação à amostra brasileira, estabelecida com base nas respostas dos participantes deste estudo, para as quatro subescalas do instrumento: faces, quadros, músicas e histórias.

Também foram calculadas as pontuações por concordância com especialistas e com a pessoa alvo, atribuindo-se um ponto toda vez que as respostas dos participantes coincidiam com as respostas dos especialistas e dos participantes que produziram os estímulos, respectivamente; ambas cedidas pelos pesquisadores americanos. A concordância com especialistas foi calculada para as subescalas faces e quadros, e a concordância com a pessoa-alvo apenas para a subescala quadros.

Finalmente, as pontuações gerais dos participantes em cada critério (consenso, especialistas e alvo) foram divididas pelo número de itens que compõem cada escala, de modo a obter sempre resultados entre 0 e 1 . As estatísticas descritivas e as consistências internas para cada tipo de pontuação são apresentadas na Tabela 1.

No geral, foram obtidos bons índices de consistência interna, com exceção da pontuação por concordância com especialistas, que se mostrou pouco abaixo do que seria aceitável. Os melhores índices foram obtidos com as pontuações baseadas na concordância com o consenso de participantes brasileiros. Estes dados não confirmam os resultados de baixa consistência interna para o critério consenso obtidos em outros estudos (Davies \& cols., 1998; Mayer \& cols., 1990); porém, segundo o critério consenso adotado nesses estudos, atribuía-se um ponto ao sujeito sempre que sua resposta coincidia ou se localizava a mais ou menos um ponto da resposta modal - critério diferente do adotado nesse estudo. Em outro estudo, cuja pontuação por concordância com o consenso foi realizada tal como no presente trabalho, as

Tabela 1

Estatisticas Descritivas e Consistências Internas da Escala de Percepção de Emocõos da MEIS

\begin{tabular}{lcccccc}
\hline & $\mathrm{N}$ & Mínimo & Máximo & $m$ & $d p$ & Coef. $\alpha$ de Cronbach \\
\hline Consenso-Faces (EUA) & 76 & 0,19 & 0,48 & 0,39 & 0,0587 & 0,79 \\
Consenso-Quadros (EUA) & 76 & 0,18 & 0,46 & 0,37 & 0,0622 & 0,84 \\
Especialistas-Faces (EUA) & 76 & 0,38 & 0,85 & 0,62 & 0,0918 & 0,60 \\
Especialistas-Quadros (EUA) & 76 & 0,40 & 0,85 & 0,67 & 0,0923 & 0,60 \\
Alvo-Quadros (EUA) & 76 & 0,27 & 0,88 & 0,68 & 0,1073 & 0,71 \\
Consenso-Faces (BR) & 76 & 0,18 & 0,50 & 0,41 & 0,0653 & 0,83 \\
Consenso-Músicas (BR) & 76 & 0,17 & 0,59 & 0,48 & 0,0840 & 0,89 \\
Consenso-Quadros (BR) & 76 & 0,17 & 0,51 & 0,41 & 0,0776 & 0,88 \\
Consenso-Histórias (BR) & 58 & 0,14 & 0,37 & 0,29 & 0,0529 & 0,86 \\
\hline Total-Consenso (BR) & 58 & 0,16 & 0,47 & 0,40 & 0,0639 & 0,96
\end{tabular}


Tabela 2

Coeficientes de Correlações de Pearson entre os Vários Critérios de Pontuação Obtidos a partir das Normas Americanas

\begin{tabular}{llllccc}
\hline $\begin{array}{l}\text { Critérios de } \\
\text { pontuação }\end{array}$ & Subescalas & \multicolumn{2}{c}{ Consenso } & Especialistas & Alvo \\
\hline \multirow{2}{*}{ Consenso } & Faces & Faces & Quadros & Faces & Quadros & Quadros \\
& Quadros & $0,633^{* *}$ & - & & & \\
\multirow{2}{*}{ Especialistas } & Faces & $-0,293^{*}$ & $-0,400^{* *}$ & - & & \\
& Quadros & 0,087 & $-0,063$ & $0,399 * *$ & - & \\
Alvo & Quadros & $0,609^{* *}$ & $0,765^{* *}$ & $-0,115$ & $0,250^{*}$ & - \\
\hline
\end{tabular}

$* p<0,05, * * p<0,01$

consistências internas da subescala verbal (histórias) foram semelhantes $(\alpha=0,92 ; \alpha=0,86$, respectivamente) (Mayer $\&$ Geher, 1996). Fica evidente, portanto, que entre as duas possibilidades de pontuação pela concordância com o consenso, o método baseado na ponderação da pontuação é mais preciso que o método baseado na resposta modal.

Uma das expectativas desse estudo era de que as pontuações baseadas nos diversos critérios utilizados apresentassem altas e significativas correlações entre si. Tais cruzamentos correlacionais são apresentados na Tabela 2.

Pode-se observar três padrões importantes: a) subescalas diferentes pontuadas pelos mesmos critérios tendem a se correlacionar positivamente; b) subescalas pontuadas pelos critérios consenso e alvo tendem a se correlacionar positivamente; c) subescalas pontuadas pelo critério especialista tendem a se correlacionar negativamente com o consenso.

Ao contrário do esperado, as correlações entre os diferentes critérios de pontuação adotados apresentaramse confusas, principalmente em relação à concordância com especialistas. Esses dados não apóiam a afirmação dos pesquisadores americanos de que "a pessoa-alvo pode ser entendida como um segundo tipo de especialista" (Mayer $\&$ cols., 2000, p. 274), pois houve muito mais semelhança entre alvo e consenso do que entre alvo e especialistas.

De fato, se por um lado faz sentido pensar na pessoaalvo como o maior especialista em suas próprias emoções, uma vez que o próprio é o único a vivenciá-las, por outro, também é legítimo supor que seu julgamento não leve em conta dois fatores que devem estar presentes no julgamento de especialistas: a imparcialidade e o conhecimento técnico sobre emoções. Assim, se pensarmos na pessoa-alvo julgando as emoções presentes em si mesma enquanto produzia os estímulos, podemos supor que ora, em razão de seus próprios mecanismos de defesa, fizesse julgamentos aceitos pela maioria (consensual); e ora, por ter conhecimentos sobre si mesmo indisponíveis aos demais (mas cognoscíveis por profissionais), fizesse julgamentos mais próximos ao de especialistas. Como as pessoas-alvo não eram nem imparciais nem especialistas em percepção de emoções, supõe-se que seu julgamento, como de fato foi detectado, se aproximasse muito mais das respostas populares do que das respostas de especialistas.

Contudo, se pensarmos em termos ideais para um teste de inteligência, teremos que concordar que o único critério que poderia ser adotado é o de especialistas. Pois, a concordância com o consenso não nos permite afirmar que um sujeito tenha maior ou menor acuidade perceptual das emoções, mas que ele concorda em maior ou em menor grau com a maioria das pessoas. O critério da resposta consensual parece mais adequado para avaliação de traços de personalidade, como no Rorschach, por exemplo, cujas respostas freqüentes são interpretadas como respostas dadas por participantes que compartilham a mesma observação da realidade com a maioria das pessoas, portanto, teriam maior facilidade para adaptação. No caso da avaliação da inteligência, nem sempre uma resposta compartilhada com a maioria da população é a melhor. Por exemplo, supondo-se que, num teste de inteligência, a dificuldade vá aumentando de item para item, é esperado que apenas uma minoria acerte os itens mais difíceis, que, segundo o critério consenso, receberiam pontuações menores do que a maioria que erra tais itens.

De qualquer forma, a avaliação dos especialistas, nesse estudo, parece não ter sido a mais adequada, pois alguma correlação positiva sempre é esperada entre as respostas consensuais e a de especialistas. De fato, os próprios pesquisadores americanos quando nos enviaram os critérios utilizados para seus estudos, recomendaram que não utilizássemos o critério de pontuação por concordância com especialistas, alegando que eles mesmos haviam abandonado esse critério devido aos maus resultados encontrados. 
Tabela 3

Coeficientes de Correlação de Pearson entre as Subescalas da Meis Pontuadas segundo Normas Brasileiras e Americanas

\begin{tabular}{llllc}
\hline & & \multicolumn{2}{c}{ Consenso } & \\
& Faces BR & Músicas BR & Quadros BR & Histórias BR \\
\hline Consenso (EUA) Faces & $0,963^{* *}$ & $0,552^{* *}$ & $0,591^{* *}$ & $0,454^{* *}$ \\
Consenso (EUA) Quadros & $0,670^{* *}$ & $0,791^{* *}$ & $0,966^{* *}$ & $0,606^{* *}$ \\
Especialistas (EUA) Faces & $-0,299^{* *}$ & $-0,240^{*}$ & $-0,351^{* *}$ & $-0,184$ \\
Especialistas (EUA) Quadros & 0,108 & $-0,155$ & $-0,121$ & 0,000 \\
Alvo (EUA) Quadros & $0,673^{* *}$ & $0,681^{* *}$ & $0,800^{* *}$ & $0,511^{* *}$ \\
\hline
\end{tabular}

$* p<0,05, * * p<0,01$

$\mathrm{Na}$ Tabela 3, são apresentadas as correlações entre todos os escores obtidos a partir da padronização americana e as pontuações por concordância com $o$ consenso, obtidas a partir da amostra brasileira utilizada nesse estudo.

As pontuações por concordância com o consenso segundo a amostra brasileira apresentaram altas e significativas correlações com as pontuações americanas, com exceção do critério concordância com especialistas, que continua apresentando correlações significativas, porém negativas com a subescala faces, e correlações nãosignificativas com a subescala quadros. Especificamente, as altas correlações encontradas entre as subescalas Faces EUA e Faces BR $(r=0,96)$, e entre Quadros EUA e Quadros BR $(r=0,97)$, nos permitem afirmar que as respostas consensuais são muito parecidas nas duas culturas. Com base nesses resultados, optou-se por utilizar somente as pontuações baseadas no critério consenso obtido a partir da amostra brasileira deste estudo.

Para verificação da hipótese levantada em relação à unifatorialidade das quatro subescalas de percepção de emoções, foi realizada uma análise fatorial por componentes principais que extraiu um único fator cujas cargas fatoriais das subescalas são apresentadas na Tabela 4.

Tabela 4

Cargas Fatoriais das Subescalas de Percepção de Emoções da Meis

\begin{tabular}{lc}
\hline Subescalas & Cargas fatoriais \\
\hline Quadros & 0,929 \\
Músicas & 0,909 \\
Faces & 0,833 \\
Histórias & 0,776 \\
\hline
\end{tabular}

Tal como hipotetizado, e corroborando outros estudos (Davies \& cols., 1998; Mayer \& cols., 2000), essa análise resultou numa solução unifatorial, capaz de explicar 74,7\% da variância total observada. Esse dado confirma a ocorrência de uma habilidade relacionada à percepção de emoções, que se supõe ligada à inteligência emocional.

\section{Análises correlacionais}

Os estudos de validade propriamente ditos, propostos nos objetivos específicos deste estudo, serão verificados através das análises correlacionais apresentadas a seguir. As correlações das escalas de percepção de emoções com as provas de raciocínio e as escalas de personalidade do 16PF, indicam em que grau a habilidade na percepção de emoções estaria relacionada a ambos os construtos inteligência e personalidade, e as correlações entre as escalas de percepção de emoções e a avaliação dos supervisores indicam em que grau a primeira é capaz de prever o desempenho dos participantes num critério de desempenho numa atividade da vida cotidiana.

Na Tabela 5, são apresentados os traços de personalidade avaliados pelo $16 \mathrm{PF}$ que apresentaram correlações estatisticamente significativas com algum aspecto da percepção de emoções.

A análise geral da Tabela 5 mostra que as correlações com traços de personalidade foram baixas como se esperava. Isto indica que a escala de percepção de emoções mede algo distinto dos traços de personalidade. Por outro lado, das hipóteses levantadas sobre as correlações entre essas duas variáveis, somente a correlação com inteligência se confirmou. Sendo assim, em seguida apresentaremos possíveis interpretações para os dados encontrados.

A subescala verbal (estímulo verbal) histórias apresentou correlação negativa e significativa apenas com o traço de autocontrole, correlações negativas e marginalmente significativas com consciência e disciplina, e correlação positiva e marginalmente significativa com inteligência. Por sua vez, as subescalas não-verbais (estímulos não-verbais) apresentaram correlações positiva e significativa com inteligência (faces) e administração da imagem (músicas e quadros), e negativa e significativa com requinte (músicas e quadros). Além disso, apresentaram correlações marginalmente significativas e negativas com imaginação 
Tabela 5

Coeficientes de Correlação de Pearson entre Percepção de Emoções e Traços de Personalidade

\begin{tabular}{lccccc}
\hline & \multicolumn{5}{c}{ Escalas de Percepção de Emoções } \\
Fatores 16 PF & Faces & Músicas & Quadros & Histórias & Total \\
\hline Adm. Imagem & 0,151 & $0,245^{*}$ & 0,193 & 0,135 & $0,272^{*}$ \\
B - Inteligência & $0,329^{* *}$ & 0,148 & 0,076 & 0,249 & 0,231 \\
G - Consciência & 0,020 & 0,020 & $-0,052$ & $-0,246$ & $-0,006$ \\
M - Imaginação & $-0,194$ & $-0,190$ & $-0,204$ & $-0,047$ & $-0,260^{*}$ \\
N - Requinte & $-0,070$ & $-0,234^{*}$ & $-0,231 *$ & $-0,103$ & $-0,200$ \\
Q1 - Abert. Novas exp. & $-0,195$ & $-0,041$ & $-0,061$ & 0,063 & $-0,065$ \\
Q3 - Disciplina & $-0,094$ & $-0,145$ & $-0,217$ & $-0,258$ & $-0,181$ \\
Extroversão & 0,133 & 0,179 & 0,215 & 0,031 & 0,185 \\
Auto controle & $-0,004$ & $-0,030$ & $-0,101$ & $-0,272^{*}$ & $-0,035$ \\
\hline
\end{tabular}

$p<0,05, * * p<0,01$

(faces, músicas e quadros), abertura a novas experiências (faces) e disciplina (quadros); e marginalmente significativas e positivas com administração da imagem e extroversão (ambas com a subescala quadros).

Esses resultados parecem indicar que a acuidade na percepção de emoções em estímulo verbal está relacionada à flexibilidade e à liberdade em relação à padrões culturalmente estabelecidos, além de um certo nível intelectual. No caso da percepção de emoções, tais pessoas parecem estabelecer seu julgamento baseado na coerência percebida entre os fatos vivenciados pela pessoa e os sentimentos correspondentes a esses fatos, sem se preocuparem se esses sentimentos são socialmente aceitos ou não. Esse processo pode estar relacionado à empatia uma vez que compreende justamente a capacidade de perceber o outro do ponto de vista do outro. De fato, um estudo sobre percepção de emoções realizado especificamente com estímulos não-verbais, mostrou haver correlação significativa entre concordância com o consenso e empatia (Mayer \& Geher, 1996), assim como, em outros estudos em que foram utilizadas as quatro subescalas de percepção de emoções, as mesmas variáveis se mostraram significativamente correlacionadas (Mayer \& cols., 1990, 2000).

As correlações apresentadas pelas escalas não-verbais (estímulos não-verbais: faces, quadros e músicas), no entanto, sugerem que altas pontuações nessas escalas são obtidas por participantes que tendem a prestar atenção e a refletir sobre dados observáveis e realidades externas de seu ambiente para formar suas percepções (M-). Quando os estímulos são artísticos (músicas e quadros) os resultados são contraditórios, pois indicam que a percepção de emoções melhora tanto quando os indivíduos são abertos aos seus próprios sentimentos e têm facilidade em falar sobre si mesmos genuinamente $(\mathrm{N}-)$, como quando tendem a administrar a imagem de acordo com o esperado socialmente (AI+). A correlação com Administração da Imagem pode estar relacionada a uma habilidade exigida pelo critério utilizado para pontuação: a concordância com o consenso. Para o estímulo faces (não artístico) é a tendência à tradicionalidade e um certo nível intelectual que se relacionam com a acuidade da percepção emocional. $\mathrm{Na}$ literatura da área, tanto a abertura aos próprios sentimentos quanto a facilidade em expressá-los são habilidades descritas como presentes em pessoas emocionalmente inteligentes (Mayer \& Salovey, 1997; Salovey \& Mayer, 1990).

O resultado total em percepção de emoções apresentou correlações significativas e positivas com administração da imagem e negativa com imaginação (M), e marginalmente significativa e positiva com inteligência. Esses resultados confirmam as expectativas com relação à existência de correlações significativas com ambos os aspectos da inteligência emocional: inteligência e personalidade. Mais especificamente, as maiores pontuações em percepção de emoções foram obtidas por pessoas que tendem a pensar de forma prática, são realistas, precisas e formais em sua relação com mundo. Além disso, a correlação do escore total em percepção de emoções com administração da imagem pode ser explicado pelo tipo de pontuação utilizado baseado na resposta consensual, pois, esse estilo de resposta é dado por pessoas que desejam ser percebidas como socialmente adequadas, ou por pessoas que realmente tendem a se comportar da maneira desejada.

As correlações entre percepção de emoções e aptidões de raciocínio (BPR-5) são apresentadas na Tabela 6 e mostram que raciocínio verbal apresentou correlação positiva e significativa somente com a subescala verbal (histórias), enquanto que o raciocínio espacial apresentou correlações positivas com todas as quatro subescalas de percepção de emoções, que foram estatisticamente significativas com faces 
Tabela 6

Coeficientes de Correlação de Pearson entre Percep̧̧ão de Emocões e Aptidões de Raciocínio

\begin{tabular}{lccccc}
\hline & Faces & Músicas & Quadros & Histórias & Total \\
\hline Raciocínio verbal & 0,076 & 0,134 & 0,090 & $0,259^{*}$ & 0,136 \\
Raciocínio espacial & $0,232^{*}$ & $0,254^{*}$ & 0,204 & 0,256 & $0,313^{*}$ \\
Escore geral de inteligência & 0,168 & 0,217 & 0,162 & $0,292^{*}$ & 0,241 \\
\hline
\end{tabular}

$* p<0,05, * * p<0,01$

Tabela 7

Coeficientes de Correlação Pearson entre Percep̧̧ão de Emoções e Desempenho no Psicodiagnóstico

\begin{tabular}{lccccc}
\hline Avaliação dos supervisores & Faces & Músicas & Quadros & Histórias & Total \\
\hline Aspectos técnicos & 0,228 & 0,020 & 0,168 & 0,205 & 0,067 \\
Aspectos emocionais & $0,243^{*}$ & 0,057 & 0,178 & 0,055 & 0,075 \\
Aspectos sociais & 0,182 & 0,123 & 0,207 & 0,115 & 0,094 \\
Desempenho geral & $0,250^{*}$ & 0,084 & 0,221 & 0,186 & 0,095 \\
\hline
\end{tabular}

e músicas, e marginalmente significativas com quadros e histórias. Músicas e histórias mantiveram correlações positivas com o escore geral de inteligência, embora no caso da subescala músicas a correlação tenha sido apenas marginalmente significativa.. Isso mostra que as escalas nãoverbais (faces, músicas e quadros) estão mais relacionadas à inteligência fluída e capacidade de processamento visual, e a escala verbal (histórias) co-varia tanto com inteligência fluída quanto com inteligência cristalizada. Além disso, as correlações apresentadas são de baixa magnitude (variam entre 0,204 e 0,292), indicando que a percepção de emoções apresenta alguma variância em comum com outras formas de inteligência aceitas como válidas, mas preserva alguma variância única para poder ser considerada como uma forma independente de inteligência, que se supõe relacionada à inteligência emocional. Resultados semelhantes foram encontrados em outro estudo envolvendo as quatro subescalas de percepção de emoções (Mayer \& cols., 2000).

Os coeficientes de correlação entre percepção de emoções e desempenho no Psicodiagnóstico (avaliação dos supervisores) são apresentados na Tabela 7. Observa-se que a subescala faces apresentou correlações positivas e estatisticamente significativas com o fator geral do desempenho no estágio em Psicodiagnóstico, e também com o fator relacionado ao preparo emocional para atendimento. Adicionalmente, apresentou correlação positiva e marginalmente significativa com o fator 1 , relacionado ao desempenho técnico no estágio. Também a subescala quadros apresentou correlações positivas e marginalmente significativas com o desempenho geral em Psicodiagnóstico e também com o fator 3, relacionado aos aspectos sociais dos atendimentos (formação de vínculo e participação no grupo de supervisão).

No entanto, nenhuma correlação significativa foi encontrada entre desempenho no Psicodiagnóstico e a escala geral de percepção de emoções. Isso indica que a solução unifatorial da escala de percepção de emoções não se mostrou capaz de prever o desempenho dos alunos em Psicodiagnóstico. Essa previsão, a rigor, só foi possível a partir da subescala faces.

Como a subescala faces correlacionou-se positiva e significativamente tanto com raciocínio espacial quanto com o desempenho geral em psicodiagnóstico, poder-se-ia levantar a hipótese de que parte da variância comum entre faces e desempenho geral no Psicodiagnóstico pudesse ser explicada pela correlação entre faces e raciocínio espacial. Para investigar tal possibilidade procedeu-se a uma correlação parcial entre o desempenho geral no Psicodiagnóstico e a subescala faces, controladas por raciocínio espacial. Verificou-se que a correlação entre as duas primeiras variáveis não perdeu significância estatística $(r=0,27 ; p=0,025)$. Esse fato mostra que a variância comum entre capacidade de perceber emoções em expressões faciais e o desempenho no Psicodiagnóstico não pode ser explicada por outra variável ligada à inteligência, confirmando que há alguma variância única relacionada à percepção de emoção, pelo menos com relação à subescala faces.

\section{Conclusão}

Esse trabalho se propôs a investigar a validade e as propriedades psicométricas de um instrumento para medida de um aspecto da inteligência emocional: a percepção de 
emoções. Para tanto, utilizou-se a subescala de percepção de emoções da Escala Multifatorial de Inteligência Emocional (Mayer \& cols., 1997) como medida desse aspecto da inteligência emocional; e como medidas de critérios externos: um instrumento para mensuração de aptidões de raciocínio verbal e espacial (BPR-5) capaz de avaliar inteligência cristalizada, inteligência fluída e processamento visual; um instrumento para avaliação de traços de personalidade (16PF); e um instrumento para coleta da avaliação do desempenho dos participantes no estágio em Psicodiagnóstico.

Entre os três diferentes critérios utilizados para pontuação das subescalas de percepção de emoções, os melhores resultados psicométricos (consistência interna) foram obtidos através da concordância com o consenso, principalmente quando se utilizou a amostra brasileira como referência para pontuação. Essa forma de pontuação apresentou-se, de modo geral, bastante similar à concordância com o alvo, mas oposta à concordância com o julgamento de especialistas. Esta última, apesar dos resultados contraditórios obtidos neste estudo, foi discutida como a forma de pontuação ideal para testes de inteligência, constituindo-se num ponto que merece ser melhor investigado e desenvolvido, para que o instrumento se aproxime de algo mais adequado para avaliação da inteligência.

Foram encontradas correlações significativas da pontuação total em percepção de emoções com inteligência e traços de personalidade. Em relação à inteligência correlacionou-se significativamente apenas com raciocínio espacial, evidenciando certa covariância com inteligência fluída e processamento visual, e independência em relação à inteligência cristalizada (raciocínio verbal). Em relação à personalidade, mostrou-se relacionada a um funcionamento mental baseado na praticidade e objetividade na percepção do mundo, características extremamente desejáveis e indispensáveis para a acuidade na percepção de emoções.

Notou-se ainda que houve diferença entre as associações de estímulos artísticos (quadros e músicas) e não-artísticos (faces). Os primeiros apareceram associados tanto a indivíduos abertos aos próprios sentimentos e que têm facilidade em falar sobre si mesmos genuinamente, quanto àqueles que tendem a administrar a imagem de acordo com o socialmente aceito, enquanto que a acuidade perceptual em estímulo não-artístico apareceu mais associada a tradicionalidade e um certo nível intelectual.

A escala geral de percepção de emoções não foi capaz de predizer o desempenho em Psicodiagnóstico; apenas a subescala faces se mostrou capaz de predizer o desempenho geral em Psicodiagnóstico, e a subescala quadros, que mostrou correlação marginalmente significativa. Demonstrou-se ainda que a covariância existente entre a percepção de emoções em faces e o desempenho geral no Psicodiagnóstico é única, pois mantêm-se estatisticamente significativa mesmo quando controlada por raciocínio espacial (outro aspecto relacionado à inteligência com a qual a percepção de emoção em faces se correlacionou significativamente).

Esse conjunto de resultados, obtidos em relação ao aspecto percepção de emoções, confirma o atual status da inteligência emocional. Alguns dados, tais como a unifatorialidade e as correlações simultâneas com variáveis relacionadas à personalidade e à inteligência, apóiam sua permanência como uma forma de inteligência; outros dados não apóiam, como a inexistência de correlação entre o conjunto unifatorial de percepção de emoções e o desempenho numa atividade cuja percepção de emoções é fundamental.

Nota-se que essa instabilidade vem se repetindo em pesquisas relacionadas à Inteligência Emocional, isto é, os dados são muito instáveis e não se reproduzem com facilidade, como seria de se esperar. Além disso, algumas vezes, são até contraditórios de uma pesquisa para outra. Por isso, alguns pesquisadores se apressam em condená-la para sempre, enquanto outros se esforçam para torná-la, de alguma forma, aceitável.

É muito provável que esse impasse continue até que se desenvolva um critério de pontuação mais adequado, capaz de proporcionar resultados mais estáveis e apropriados para uma avaliação de inteligência. É esse exercício científico que pode conduzir à concordância entre os especialistas, ou demonstrar efetivamente que o construto em questão não é viável.

\section{Referências}

BarOn, R. (1996). BarOn Emotional Quotient Inventory. New York: Multi-Health Systems.

BarOn, R. (1997). Development of the BarOn EQ-i: A measure of emotional and social intelligence. Trabalho apresentado na $105^{\mathrm{a}}$ Convenção Annual da American Psychological Association, Chicago, EUA.

Bueno, J. M. H. \& Primi, R. (2003). Escala para avaliação do desempenho de alunos de Psicologia no estágio em Psicodiagnóstico. Em VI Congresso Nacional de Psicologia Escolar e Educacional, Anais, no prelo, Salvador, BA.

Cattell, R. B., Cattell, A. K. S. \& Cattell, H. E. P. (1993). Questionário 16PF (5 ed.). Rio de Janeiro: CEPA.

Davies, M., Stankov, L. \& Roberts, R. D. (1998). Emotional intelligence: In search of an elusive construct. Journal of Personality and Social Psychology, 75, 989-1015.

Mayer, J. D. \& Geher, G. (1996). Emotional intelligence and the identification of emotion. Intelligence, 22, 89-113.

Mayer, J. D. \& Salovey, P. (1997). What is emotional intelligence? Em P. Salovey \& D. J. Sluyter (Orgs.), Emotional development and emotional intelligence: Implications for Educators (pp. 3-31). New York: Basic Books.

Mayer, J. D., DiPaolo, M. T. \& Salovey, P. (1990). Perceiving affective content in ambiguous visual stimuli: A component of emotional intelligence. Journal of Personality Assessment, 54, 772-781. 
Mayer, J. D., Salovey, P. \& Caruso, D. (1997). Emotional IQ test [CD ROM]. Needham, MA: Virtual Knowledge.

Mayer, J. D., Salovey, P. \& Caruso, D. (2000). Emotional intelligence meets stadards for an intelligence. Intelligence, 27, 267-298.

Primi, R. \& Almeida, L. S. (2000a). Estudo de validação da Bateria de Provas de Raciocínio (BPR-5). Psicologia: Teoria e Pesquisa, 16, 165-173.

Primi, R. \& Almeida, L. S. (2000b). Baterias de Provas de Raciocinio (BPR-5): Manual técnico. São Paulo: Casa do Psicólogo.

Primi, R., Bighetti, C., Munhoz, A. H., Noronha, A. P. P., Polydoro, S. A. J., Di Nucci, E. P. \& Pellegrini, M. C. K. (2002). Personalidade, interesses e habilidades: Um estudo correlacional. Avaliação Psicológica, 1, 61-72.

Salovey, P. \& Mayer, J. D. (1990). Emotional intelligence. Imagination, Cognition and Personality, 9, 185-211.
Siqueira, M. M. M., Barbosa, N. C. \& Alves, M. T. (1999). Construção e validação fatorial de uma Medida de Inteligência Emocional. Psicologia: Teoria e Pesquisa, 15,143-152.

Thorndike, E. L. (1920). Intelligence and its uses. Harper's Magazine, 140.

Vendrusculo, E. A. B. (2002). Questionário de Dezesseis Fatores de Personalidade - 16 PF: Evidências de precisão e validade em estudantes universitários. Dissertação de Mestrado não-publicada, Programa de Estudos Pós-Graduados em Psicologia, Universidade São Francisco. Itatiba, SP.

Sobre os autores

José Maurício Haas Bueno é Mestre em Psicologia pela Universidade São Francisco. É Professor de disciplinas relacionadas à Avaliação Psicológica na Universidade São Francisco e Universidade Presbiteriana Mackenzie.

Ricardo Primi é Doutor em Psicologia Escolar e do Desenvolvimento Humano pela Universidade de São Paulo, com parte desenvolvida na Yale University (EUA). É Coordenador do Laboratório de Avaliação Psicológica e Educacional (LabAPE) e do Programa de Estudos Pós-Graduados em Psicologia da Universidade São Francisco. 